\title{
Dyslipidemic profile in Type 2 Diabetes Mellitus: A hospital- based study from Eastern Nepal
}

Das $\mathrm{BKL}^{1 *}$, Prassan $\mathrm{N}^{2}$, Ansari $\mathrm{MF}^{3}$, Panday $\mathrm{MF}^{4}$, Agrawal $\mathrm{K}^{5}$, Niraula $\mathrm{A}^{6}$

*Corresponding author:

Dr. Binod Kumar Lal Das, Associate Professor, Department of Biochemistry, B.P. Koirala Institute of Health Sciences, Dharan, Nepal

Email: binod.das@bpkihs.edu ORCID

Information about the article:

Received: Nov 29, 2020

Accepted: Dec. 20, 2020

Published online: Dec. 31, 2020

Cite this article:

Das BKL, Prassan N, Ansari MF, Panday MF, Agrawal K, Niraula A. Dyslipidemic profile in Type 2 Diabetes Mellitus: A hospital-based study from Eastern Nepal. Journal of Biomedical Sciences. 2020; 7(2):64-70

\section{Publisher}

Nepal Health Research Society, Bashundhara -6, Gokarnesowor Municipality, Kathmandu, Nepal eISSN 2382-5545, ISSN 2676-1343 (Print)

(C) The Author(s). 2020

Content licensing: CC BY 4.0

\section{ABSTRACT}

\section{Background}

Dyslipidemia is highly prevalent in Type 2 Diabetes Mellitus (T2DM). It plays a major role in the pathogenesis for diabetic complications. This study intends to exemplify the pattern of dyslipidemia prevalent in T2DM patients attending tertiary care centre of Eastern Nepal.

\section{Material and methods}

This is a hospital based cross-sectional study conducted in the T2DM patients visiting the routine biochemistry laboratory for their routine blood investigations. 226 patients were included who fulfilled the inclusion criteria. Biochemical parameters were analyzed in routine biochemistry laboratory in cobas c311 autoanalyzer.

\section{Results}

Out of the 226 T2DM patients, 51\% were female and $49 \%$ were male respectively. The mean age group was $54.15 \pm$ 12.62 years. Mean value of, HbA1c level, total cholesterol, TG, HDL and LDL was $8.16 \pm 2.59 \%$, $289.04 \pm 47.83$, $297.77 \pm 119.64$, $35.62 \pm 12.64140 .88 \pm 40.58$ respectively. HbA1c was significantly correlated with the lipid profile in T2DM patients $(\mathrm{p}<0.05)$.

\section{Conclusion}

The findings from the present study depicts that the prevalence of dyslipidemia is higher in T2DM in our centre with hypertriglyceridemia being the major type of dyslipidemia in these patients. In addition, male exhibited higher rate of dyslipidemia compare to their female counterparts respectively.

\section{Keywords}

Dyslipidemia, Hypertriglyceridemia, Type 2 Diabetes Mellitus, Lipid Profile 


\section{Background}

Type 2 Diabetes Mellitus (T2DM) is a group of metabolic disorders characterized by varied degrees of insulin resistance, impaired insulin secretion, and increased glucose production [1]. Globally, there is an increasing trend of cases of Diabetes Mellitus every year. The prevalence has increased from 327 million in the population of age group of 20-64 years with the estimated rise of 438 million among those aged 20-64 years in 2045 respectively [2]. It is considered as a major risk factors for the development of the atherosclerosis subsequently leading to cardiovascular disease i.e., atherosclerotic cardiovascular disease (ASCVD). Atherogenic dyslipidemia is the major cause attributed to the development of ASCVD [3]. Among the coronary artery disease, one with the common occurrence is the cardiovascular disorder and cerebrovascular accident. Hyperglycemia in T2DM for a longer period results in changes in the chemical properties of the proteins (glycosylation) especially the connective tissue proteins i.e. collagen crosslinking and matrix proteins present in the wall of arteries [4]. The major consequence of this deleterious process is the development of endothelial function ultimately resulting in atherosclerosis. There is a lack of insulin action that leads to the alteration in carbohydrate, fat and protein metabolism [5]. Relatively insulin deficiency, insulin resistance and obesity are concomitant to hypertriglyceridemia, decreased serum HDL cholesterol and intermittently associated with high serum LDL cholesterol in T2DM. T2DM is associated with dyslipidemia which is demonstrated as raised low-density lipoprotein cholesterol (LDL-C), reduced high density lipoprotein cholesterol (HDL-C) levels or increased triglyceride (TG) levels [6-9]. Increased triglyceride levels is an independent risk factor for coronary artery disease. The major concern for Dyslipidemia in T2DM is due to its utmost risk for the development of macrovascular complications affecting 10$73 \%$ of the diabetic patients [10]. Also, the expert reports from the panel on Detection, Evaluation, and Treatment of High Blood Cholesterol in Adults (Adult Treatment Panel III or ATP III) has depicted that the Diabetes Mellitus comparable to the coronary artery disease (CHD), summiting it to the highest risk category [11-14]. Hence, we intended to determine the pattern of lipid profile prevalent in patients of Type II Diabetes Mellitus and to find out if there is any relationship of dyslipidemia with age, sex and obesity in Type II Diabetes Mellitus.

\section{Material and methods}

\section{Study design and the participants}

This was a hospital based comparative cross-sectional study conducted in the Department of Biochemistry at B. P. Koirala Institute of Health Sciences (BPKIHS), Dharan from June - November 2019.

\section{Data collection}

Blood was collected in serum vial and EDTA vial from the study population for lipid profile, fasting, postprandial blood glucose and HbA1c respectively. 10-12 hours of fasting was ensured in the study patients for lipid profile analysis and the blood sample was withdrawn. Serum was separated within 30 min of blood collection.

\section{Serum Glucose estimation}

Fasting blood glucose (FPG) and Postprandial blood glucose (PPG) was done by Hexokinase Method (Cobas c311 autoanalyzer) [16-17]. FPG and PPG is expressed in $\mathrm{mg} / \mathrm{dl}$. Hexokinase catalyzes the phosphorylation of glucose to glucose-6-phosphate by ATP.

\section{Serum Cholesterol estimation}

Serum Cholesterol was done by enzymatic, colorimetric method [18] in cobas c311 autoanalyzer.

\section{Serum Triglycerides estimation}

Serum triglycerides estimation was done by enzymatic colorimetric test [19] in cobas c3111 autoanalyzer.

Serum HDL and LDL estimation: Serum HDL and LDL estimation was done by Homogeneous enzymatic colorimetric test20-21 in cobas c311 autoanalyzer.

\section{HbA1c estimation}

HbA1c was done by turbidimetric inhibition immunoassay (TINIA) method in Cobas c311 Autoanalyzer [16]. The range for HbA1c was taken as $4.5-6.3 \%$.

HbA1c determination was based on the turbidimetric inhibition immunoassay (TINIA) for hemolyzed whole blood.

- Glycohemoglobin (HbA1c) in the sample reacts with anti-HbA1c antibody to form soluble antigenantibody complexes. Only one specific HbA1c antibody site is present on the HbA1c molecule, complex formation does not take place.

- Addition of R2 (Polyhapten reagent) and start of reaction: The polyhaptens react with excess antiHbA1c antibodies to form an insoluble antibodypolyhapten complex measured turbidimetrically.

\section{Inclusion criteria}

Patients diagnosed with Type 2 Diabetes Mellitus and aged 18-55 years. All newly diagnosed and follow-up cases of T2DM visiting the laboratory for their blood investigations was included in the study.

Control sample were obtained from apparently healthy persons who came for general health check-up after obtaining informed consent.

\section{Exclusion Criteria}

Pregnant females, patients diagnosed of Type 1 Diabetes Mellitus and patients taking drugs like corticosteroids and other systemic diseases were excluded from the study. 


\section{Sample size calculation}

Two hundred and twenty-six patients and one hundred thirteen apparently healthy controls were enrolled from routine clinical biochemistry laboratory at B.P. Koirala Institute of Health Sciences. Sample size was calculated based on a similar study done in eastern Nepal in 2009 by Regmi et al15 which reported the prevalence of dyslipidemia in T2DM to be $63.8 \%$.

\section{Sampling technique}

Diabetic patients were recruited from clinical laboratory services (Department of Biochemistry) by convenient sampling technique and the biochemical parameters was assessed in Department of Biochemistry, BPKIHS.

\section{Data management and statistical analysis}

Data was collected and entered using Microsoft Excel ${ }^{\mathrm{TM}}$ and analyzed using Statistical Package of Social science (SPSS) version 11.5 (Chicago Inc). Data was expressed in terms of figure, percentage, mean and standard deviation. Chi-square test was used to compare the categorical variables and independent t-test was used to compare the mean difference between case and control groups respectively. Pearson's correlation was applied to correlate HbA1c with lipid profile, fasting and postprandial glucose levels. Level of significance was considered at $95 \%$ i.e. $p$ value $<0.05$ was considered to be statistically significant.

\section{Ethical committee approval}

Ethical clearance was obtained from the Departmental Research Unit Committee (DRU) of Department of Biochemistry, B.P. Koirala Institute of Health Sciences (Research Code number: DRU/BIOCH/03/2019).

\section{Results}

The study population included 226 patients diagnosed with T2DM and 113 healthy controls. Demographic data and glycemic status of the T2DM and healthy controls has been depicted in Table 1.

\begin{tabular}{lccc}
\hline \multicolumn{3}{l}{ Table 1: Demographic profile and glycemic status in the } \\
study population
\end{tabular}

Serum total cholesterol, Triglycerides, LDL was found to be significantly higher and HDL was significantly lower in the Type 2 DM patients compared to the healthy controls (Table 2).

\begin{tabular}{|c|c|c|c|}
\hline \multicolumn{4}{|c|}{ Table 2: Lipid Profile in the study population } \\
\hline Lipid Profile & Type 2 DM & Control & p value \\
\hline $\begin{array}{l}\text { Total Cholesterol } \\
\text { (mg/dl) }\end{array}$ & $\begin{array}{l}289.04 \pm \\
47.83\end{array}$ & $145.20 \pm 45.40$ & $<0.001^{*}$ \\
\hline $\begin{array}{l}\text { Triglycerides } \\
\text { (mg/dl) }\end{array}$ & $\begin{array}{l}297.77 \pm \\
119.64\end{array}$ & $115.55 \pm 38.77$ & $<0.001^{*}$ \\
\hline $\begin{array}{l}\text { High Density } \\
\text { Lipoprotein } \\
\text { (mg/dl) }\end{array}$ & $35.62 \pm 12.64$ & $50.55 \pm 18.79$ & $<0.05^{*}$ \\
\hline $\begin{array}{l}\text { Low-Density } \\
\text { Lipoprotein } \\
\text { (mg/dl) }\end{array}$ & $\begin{array}{l}140.88 \pm \\
40.58\end{array}$ & $90.45 \pm 23.55$ & $<0.04 *$ \\
\hline
\end{tabular}

\begin{tabular}{lccc}
\hline \multicolumn{4}{c}{ Table 3: Comparison of Lipid Profile parameters and } \\
Glycemic status in male and female patients \\
\hline Variables & Male & Female & p value \\
FPG & $184.44 \pm 90.20$ & $169.35 \pm 73.25$ & 0.16 \\
PPG & $288.22 \pm$ & $269.53 \pm$ & 0.31 \\
& 157.16 & 121.60 & \\
HbA1c & $8.22 \pm 2.73$ & $8.11 \pm 2.46$ & 0.76 \\
TC & $192.28 \pm 55.47$ & $186.65 \pm 39.61$ & 0.38 \\
HDL & $43.96 \pm 11.45$ & $47.17 \pm 13.47$ & $0.04^{*}$ \\
LDL & $114.16 \pm 46.94$ & $107.66 \pm 33.07$ & 0.23 \\
TG & $206.15 \pm$ & $189.53 \pm$ & 0.29 \\
& 130.49 & 107.86 & \\
\hline
\end{tabular}

p value $<0.05$, statistically significant

Comparison of glycemic and lipid parameters between male and female revealed that only HDL was found to be significantly higher in female compared to male type $2 \mathrm{DM}$ patients (Table 3).

\begin{tabular}{|c|c|c|c|c|}
\hline $\begin{array}{l}\text { Abnormal } \\
\text { serum lipid } \\
\text { values }\end{array}$ & $\begin{array}{l}\text { Mean } \pm \\
\text { S.D. }\end{array}$ & Male & Female & $\mathrm{p}$ value \\
\hline $\begin{array}{l}\text { Total } \\
\text { Cholesterol } \\
(>200 \mathrm{mg} / \mathrm{dl})\end{array}$ & $\begin{array}{l}337.62 \pm \\
3.77\end{array}$ & $\begin{array}{l}106 \\
(51 \%)\end{array}$ & 96 (42\%) & 0.43 \\
\hline $\begin{array}{l}\text { Triglycerides } \\
\text { (>150 mg/dl) }\end{array}$ & $\begin{array}{l}367.54 \pm \\
10.63\end{array}$ & $\begin{array}{l}120 \\
(53 \%)\end{array}$ & $100(44 \%)$ & 0.51 \\
\hline $\begin{array}{l}\text { LDL (> } 100 \\
\mathrm{mg} / \mathrm{dl})\end{array}$ & $\begin{array}{l}168.87 \pm \\
2.87\end{array}$ & 98 (43\%) & 78 (34\%) & 0.34 \\
\hline $\begin{array}{l}\text { HDL }(<40 \\
\mathrm{mg} / \mathrm{dl})\end{array}$ & $\begin{array}{l}34.67 \pm \\
0.43\end{array}$ & 79 (35\%) & 59 (26\%) & 0.15 \\
\hline
\end{tabular}

Lipid profile of the study population reveals that dyslipidemia was prevalent in $51 \%$ of the male and $42 \%$ of the female. Pattern of dyslipidemia between male and female patients showed that though dyslipidemia was highly prevalent in both of the gender, but the difference was insignificant (Table 4).

\section{Discussion}

Dyslipidemia is one of the focal concerns in patients with T2DM, as it is the major risk factor related to further complications of T2DM [22]. Studies have shown that atherogenic dyslipidemia due to insulin resistance is exaggerated by the hyperglycemic state and lipotoxicity; all of these factors collectively lead to increased threat to cardiovascular system [23]. 


\begin{tabular}{|c|c|c|c|c|c|}
\hline Parameters & HbA1c & TC & TG & HDL & LDL \\
\hline & & $0.64 *$ & $0.43 *$ & $-0.56 * *$ & $0.50 *$ \\
\hline HbA1c & - & 0.02 & 0.02 & $<0.001$ & 0.03 \\
\hline TC & $\begin{array}{l}0.64^{*} \\
0.02\end{array}$ & - & $\begin{array}{l}0.29 * * \\
<0.001\end{array}$ & $\begin{array}{l}-0.19 * \\
0.004\end{array}$ & $\begin{array}{l}0.91 * * \\
<0.001\end{array}$ \\
\hline TG & $\begin{array}{l}0.43 \\
0.02 *\end{array}$ & $\begin{array}{l}0.29 * * \\
<0.001\end{array}$ & - & $\begin{array}{l}-0.40 * * \\
0.001\end{array}$ & $\begin{array}{l}0.16^{*} \\
<0.01\end{array}$ \\
\hline HDL & $\begin{array}{l}-0.56^{* *} \\
<0.001\end{array}$ & $\begin{array}{l}-0.19^{*} \\
0.004\end{array}$ & $\begin{array}{l}-0.400 * * \\
0.001\end{array}$ & - & $\begin{array}{l}0.092 \\
0.17\end{array}$ \\
\hline LDL & $\begin{array}{l}0.50^{*} \\
0.03\end{array}$ & $\begin{array}{l}0.91 * * \\
<0.001\end{array}$ & $\begin{array}{l}0.16^{*} \\
<0.01\end{array}$ & $\begin{array}{l}0.092 \\
0.17\end{array}$ & - \\
\hline
\end{tabular}

${ }^{* *} \mathrm{p}<0.001 ;{ }^{*} \mathrm{p}<0.05$, statistically significant

Pearson's correlation for correlating the lipid profile parameters with the marker for glycemic control (HbA1c) demonstrated that TC, TG and HDL was significantly correlated with HbA1c, while there was a negative correlation between HDL and HbA1c $(\mathrm{p}<0.05)$ (Table 5).

The present study depicted that dyslipidemia is highly prevalent in the T2DM patients of Eastern Nepal. The finding was in accordance with the study done in other parts of Nepal [24-25]. Associated co-morbidities specifically dyslipidemia and hypertension in T2DM increases the 2-4fold risk for the development for coronary artery disease compared to non-diabetic patients [26-27].

Our study depicted female preponderance in T2DM with $51 \%$ of female with T2DM. But, in contrast male patients showed higher prevalence of dyslipidemia i.e., $66 \%$ of male showed dyslipidemia. This is in accordance with the studies reported by Pandeya et al [25] and Shrestha et al [26] who reported the prevalence of dyslipidemia in 59\% and $85 \%$ of males in the study population respectively. Studies have depicted that glycation of proteins tends to be higher in the male patients compared to their female counterparts. The reason postulated for this could be due to the presence of some physiological state like pregnancy or metabolic conditions like obesity rather than sex specific genetic tendency [27]. The mean age in the present study is $54.15 \pm$ 12.62 years which exhibits the presence of T2DM in older population. This is in accordance with the studies published by WHO 1998. Mean BMI (28.5 \pm 4.7$)$ was higher in the T2DM patients which was in accordance to the study reported by Pokharel et al [24], Pandeya et al [25] respectively. Higher BMI which is directly associated with the abdominal obesity is recognized as one of the risk factors for metabolic risk factors, incident cardiovascular events and increased mortality respectively. There is the direct risk which is linked with the presence of visceral adipose tissue (VAT) that can lead to insulin resistance, dyslipidemia and hypertension [27].

The present study intended to evaluate the pattern of lipid profile and its correlation with HBA1c in T2DM patients. Assessment of lipid profile with the HbA1c level depicts that there was no significant difference in the lipid profile parameters in male and females. Few factors predispose females for high risk of development of dyslipidemia like the effect of sex hormones on body fat distribution leading to the differences in altered lipoproteins metabolism [28].

We further evaluated the correlation of lipid profile with glycemic status in T2DM patients. The findings revealed that $\mathrm{HbA1c}$ which represents the long-term glycemic control was significantly correlated with HDL-Cholesterol levels. While there was no significant correlation with other parameters of lipid profile (TC, LDL and TG). This finding was in accordance with the study reported by Sapkota et al [29] who had reported significant correlation between HbA1c and lipid profile parameters. There is an established fact for the direct association of long-standing hyperglycemia and T2DM complicated with severe dyslipidemia consequently leading to cardiovascular events. The presence of these risk factors upsurges 2-4-fold of increased menace for the development of coronary heart disease and other cardiovascular events respectively. In addition, current treatment protocols target to prioritize the patients with poor glycemic control to achieve near normal to sub normal blood glucose levels in a prospect to prevent the progression of dyslipidemia and further events related to it [23]. Subsequently, our study reports a high prevalence of increased total cholesterol, raised triglycerides, high LDL-C and low HDL-C levels in patients with poor glycemic control as shown by increased HbA1cHbA1C levels which are well known risk factors for cardiovascular diseases.

Insulin, the hormone for glucose homeostasis regulates the apolipoprotein production in liver and modulates the enzymatic activity of lipoprotein lipase and Cholesterol ester transport protein. Hence, insulin resistance or decreased insulin action collectively leads to dyslipidemia in Diabetes mellitus [30]. Adversely, insulin deficiency reduces the activity of hepatic lipase and several steps in the production of biologically active LpL may be altered in Diabetic patients [31].

The type of lipid abnormalities is variable in T2DM patients ranging from dyslipidemia to isolated lipid parameter abnormality [27]. The present study demonstrated a higher rate of dyslipidemia in T2DM i.e., 51\% of T2DM patients has dyslipidemia. This was slightly lower compared to the other studies reported from other part of the country [2527]. Our research findings illustrated that T2DM patients had significantly higher level of triglycerides (TG) level, increased total cholesterol and LDL-Cholesterol and lower HDL level which was in line with the similar studies [2527]. Uncontrolled state of T2DM characterized by hyperglycemia and insulin resistance is the major causative factor contributing for dyslipidemia [27,32-34]. Among the lipid parameters, isolated hypertriglyceridemia was the most common in T2DM patients. Similar findings were reported by other studies as well [25,35-38]. 


\section{Conclusion}

The present study finding depicts that dyslipidemia is highly prevalent in T2DM. The coexistence of dyslipidemia in T2DM encompasses for increased cardiovascular risk. Hence, the indication of lifestyle modification and lipid lowering therapy as a prophylaxis for cardiovascular disease in T2DM is done by continuous monitoring of lipid profile and glycemic status in T2DM patients.

\section{Limitation and future scope of the study}

This was a hospital based cross-sectional study reported from a single setting done in a limited sample size. Additional markers of inflammation like hs-CRP, IL-6 could not be incorporated in the present study due to resource constraints.

A large multi centric cohort study could be conducted in future taking the baseline variables like FPG, PP, HbA1c, Lipid profile and Apolipoproteins in Type 2 Diabetes Mellitus.

\section{Relevance of the study}

This study will be a baseline study for the further larger study if conducted in the similar setting. Also, the present study shows the status of common co-morbidity i.e., Dyslipidemia associated with Type 2 Diabetes Mellitus patients of Eastern Nepal.

\section{Abbreviations}

ATP- Adult Treatment Panel Guidelines, CHD-Coronary Artery Disease, HDL- High Density Lipoprotein, HDLHigh Density Lipoproteins, LDL- Low Density Lipoprotein T2DM: Type 2 Diabetes Mellitus, TC- Total Cholesterol TG- Triglycerides

\section{Acknowledgments}

Dr. BKLD would like to acknowledge his alma mater B.P. Koirala Institute of Health Sciences, Dharan, Nepal, for providing the platform to conduct the study. He also expresses his sincere gratitude to the study participants without whom the study would have been impossible.

\section{Authors' contribution}

a. Study planning: BKLD, AN

b. Data collection: NP. MFA, KA, SP, AN

c. Data analysis/ interpretation: NP, MFA, KA, SP, AN

d. Manuscript writing: BKLD, NP, AN

e. Manuscript revision: BKLD, AN

f. Final approval: BKLD, NP. MFA, KA, SP, AN

g. Agreement to be accountable for all aspects of the work: BKLD, NP. MFA, KA, SP, AN

\section{Funding}

No funding has been obtained to conduct the study.

\section{Availability of data and materials}

The data generated and analyzed during the study are not publicly available due to the restriction in disclosure of the patient's details including identification but can be made available by the author on rational request.

\section{Competing interests}

None declared.

\section{Publisher's Note}

NHRS remains neutral with regard to jurisdictional claims in published maps and institutional affiliations.

The publisher shall not be legally responsible for any types of loss, actions, claims, proceedings, demand or costs or damages whatsoever or howsoever caused arising directly or indirectly in connection with or arising out of the use of this material.

\section{Author information}

${ }^{1}$ Dr. Binod Kumar Lal Das, Associate Professor, Department of Biochemistry, ORCID

${ }^{2}$ Netra Prassan, MBBS 4th Year Student, Nepal ORCID

${ }^{3}$ Mohammad Faiz Ansari, MBBS 4th Year Student, ORCID

${ }^{4}$ Kanishk Agrawal, MBBS 4th Year Student, ORCID

${ }^{5}$ Saloni Tripathi, MBBS 4th Year Student, ORCID

${ }^{6}$ Dr. Apeksha Niraula, Assistant Professor, Department of Biochemistry, ORCID

${ }^{1,6}$ Department of Biochemistry, B.P. Koirala Institute of Health Sciences, Dharan, Nepal

${ }^{2-5}$ MBBS 4th Year Student, B.P. Koirala Institute of Health Sciences, Dharan, Nepal

\section{References}

1. Powers AC, Niswender KD, Molina EC. Diabetes Mellitus: Diagnosis, Classifcation, and Pathophysiology. In: Harrison's Principles of Internal Medicine; 2018. p. 2850-2859.

2. Bali K, Vij AS. Pattern of dyslipidemia in Type 2 Diabetes Mellitus in Punjab. Int J Res Med Sci. 2016;4(3):809-812 https://doi.org/10.18203/23206012.ijrms20160523

3. Devrajani, B.R., S.Z. Shah, A.A. Soomro and T. Devrajani, 2010. Type 2 diabetes mellitus: A risk community factor for Helicobacter pylori infection: A hospital-based case-control study. Int. J. Diabetes Dev. Ctries, 30(1): 22-6. https://doi.org/10.4103/0973-3930.60008

4. Abou-Seif, M.A., Youssef, A.A. Evaluation of some biochemical changes in diabetic patients. Clin. Chim. Acta. 2004. 346: 161-70. https://doi.org/10.1016/j.cccn.2004.03.030

5. Garg A, Grundy SM. Management of dyslipidemia in NIDDM. Diabetes Care. 1990; 13: 153. https://doi.org/10.2337/diacare.13.2.153 
6. O'Brien T, Nguyen TT, Zimmerman BR. Hyperlipidemia and diabetes mellitus. Mayo Clin Proc.1998; 73: 969. https://doi.org/10.4065/73.10.969

7. Hennes MM, O'Shaughnessy IM, Kelly TM. Insulin-resistant lipolysis in abdominally obese hypertensive individuals. Hypertension. 1996; 28:120-6. https://doi.org/10.1161/01.HYP.28.1.120

8. Barker DJP, Hales CN, Fall C. Type 2 diabetes mellitus, hypertension and hyperlipidemia (syndrome $\mathrm{X}$ ): relation to reduced fetal growth. Diabetologia. 1998; 36: 62-7. https://doi.org/10.1007/BF00399095

9. Chattanda SP, Mgonda YM. Diabetic dyslipidemia among diabetic patients attending specialized clinics in Dar es Salaam. Tanzania Med. J. 2008; 23(1):

08-11. https://doi.org/10.4314/tmj.v23i1.39221

10. Expert Panel on Detection, Evaluation, and Treatment of High Blood Cholesterol in Adults: Executive summary of the third report of the national cholesterol education program (NCEP) expert panel on detection, evaluation, and treatment of high blood cholesterol in adults (Adult Treatment Panel III). JAMA. 2001; 285:2486-97.

https://doi.org/10.1001/jama.285.19.2486

11. Grundy SM, Cleeman JI, Merz CN, Brewer HB Jr, Clark LT, Hunninghake DB et al. National Heart, Lung, and Blood Institute, American College of Cardiology Foundation, American Heart Association: Implications of recent clinical trials for the National Cholesterol Education Program Adult Treatment Panel III guidelines. Circulation. 2004; 110: 227-39. https://doi.org/10.1161/01.CIR.0000133317.49796 $.0 \mathrm{E}$

12. Lloyd-Jones DM. Cardiovascular risk prediction: basic concepts, current status, and future directions. Circulation. 2010; 121: 1768-1777. 4. https://doi.org/10.1161/CIRCULATIONAHA.109. $\underline{849166}$

13. Tzoulaki I, Liberopoulos G, Ioannidis JP. Assessment of claims of improved prediction beyond the Framingham risk score. JAMA. 2009; 302:2345-52.

https://doi.org/10.1001/jama.2009.1757

14. Cho YK, Jung CH, Kang YM, Hwang JY, Kim EH, Yang DH et al. 2013 ACC/AHA Cholesterol Guideline versus 2004 NCEP ATP III Guideline in the Prediction of Coronary Artery Calcification Progression in a Korean Population. J Am Heart Assoc. 2016; 5: e003410 https://doi.org/10.1161/JAHA.116.003410

15. Regmi P , Gyawali P, Shrestha R, Sigdel M , Mehta KD, Majhi KD. Pattern of Dyslipidemia in
Type II Diabetic Subjects in Eastern Nepal. JNAMLS. 2009; 10 (1):11-3.

16. Kunst A, Draeger B, Ziegenhorn J. In: Bergmeyer. Methods of Enzymatic Analysis, 3rd ed. Volume VI, Metabolites 1: Carbohydrates. 1984:163-172.

17. Tietz NW, ed. Clinical Guide to Laboratory Tests, 4th ed. Philadelphia. WB Saunders Company, 2006:444-51

18. Siedel J, Hägele EO, Ziegenhorn J, Wahlefeld AW. Reagent for the enzymatic determination of serum total cholesterol with improved lipolytic efficiency. Clin Chem 1983;29:1075-1080 https://doi.org/10.1093/clinchem/29.6.1075

19. Siedel J, Schmuck R, Staepels J, Town MH. Long term stable, liquid ready to use monoreagent for the enzymatic assay of serum or plasma triglycerides (GPOPAP method). AACC Meeting Abstract 34. Clin Chem. 1993;39:1127. https://doi.org/10.1111/j.15563502.1993.tb00530.x

20. Sugiuchi H, Uji Y, Okabe H, Irie T, Uekama K, Kayahara N, Miyauchi K. et al. Direct Measurement of High-Density Lipoprotein Cholesterol in Serum with Polyethylene GlycolModified Enzymes and Sulfated $\alpha$-Cyclodextrin. Clin Chem 1995; 41: 717-23. https://doi.org/10.1093/clinchem/41.5.717

21. Rifai N, Warnick GR, McNamara JR, Belcher JD, Grinstead GF et al Measurement of Low-DensityLipoprotein Cholesterol in Serum: a Status Report. Clin Chem 1992; 38:150-60. https://doi.org/10.1093/clinchem/38.1.150

22. Mooradian AD. Dyslipidemia in type 2 diabetes mellitus. Nat Clin Pract Endocrinol Metab. 2009; 5(3):150-9. https://doi.org/10.1038/ncpendmet1066

23. Ginsberg HN, Zhang YL, Hernandez-Ono A. Metabolic syndrome: focus on dyslipidemia. Obesity (Silver Spring) 2006; 14(Suppl 1):41S-9S. https://doi.org/10.1038/oby.2006.281

24. Pokharel DR, Khadka D, Sigdel M, Yadav NK, Acharya S, Kafle R et al Prevalence and pattern of dyslipidemia in Nepalese individuals with type 2 diabetes. BMC Res Notes.2017; 10:146: 1-11. DOI 10.1186/s13104-017-2465-4. https://doi.org/10.1186/s13104-017-2465-4

25. Pandeya A, Sharma M, Regmi P, Basukala A, Lamsal M. Pattern of dyslipidemia and evaluation of non-HDL cholesterol as a marker of risk factor for cardiovascular disease in type 2 diabetes mellitus. Nepal Med Coll J. 2012; 14(4): 278-82.

26. Shrestha HK, Khanal L. Prevalence and pattern of dyslipidemia among type 2 diabetes mellitus patients in a tertiary center hospital of Nepal. Endocrinol Metab Int J. 2017; 4(3):54-6. https://doi.org/10.15406/emij.2017.04.00084 
27. Stratton IM, Adler AI, Neil HA, Matthews DR, Manley SE, Cull CA et al Association of glycaemia with macrovascular and micro vascular complications of Type 2 Diabetes (UKPDS35); Prospective Observational Study. BMJ. 2000; 321(7258):405-12.

https://doi.org/10.1136/bmj.321.7258.405

28. Ahmed N, Khan J, Siddiqui TS. Frequency of dyslipidemia in type 2 diabetes mellitus in patients of Hazara division. J Ayub Med coll Abbottabad. 2008; 20(2):51-4.

29. Sapkota LB, Thapa S. Pattern of Dyslipidemia in Type 2 Diabetic Patients attending Tertiary Care Centre of Nepal. EC Endocrinology and Metabolic Research. 2019; 4(9): 15-22.

30. Ormazabal V, Nair S, Elfeky O, Aguayo C, Salomon C, Zuniga FA. Association between insulin resistance and the development of cardiovascular disease. Cardiovasc Diabetol. 2018; $17: 122$.

https://doi.org/10.1186/s12933-018-0762-4

31. Baynes C, Henderson AD, Anyaoku V, Richmond W, Hughes CL, Johnston G, Elkeles RS. The Role of Insulin Insensitivity and Hepatic Lipase in the Dyslipidemia of Type 2 Diabetes. Diabet Med. 1991; 8(6):560-6.

https://doi.org/10.1111/j.14645491.1991.tb01652.x

32. Spiller S, Li Y, Blüher M, Welch L Hoffmann R. Diagnostic Accuracy of Protein Glycation Sites in Long-Term Controlled Patients with Type 2 Diabetes Mellitus and Their Prognostic Potential for Early Diagnosis. Pharmaceuticals.2018; 11 (38): 1-13. https://doi.org/10.3390/ph11020038

33. Huxley R, Mendis S, Zheleznyakov E, Reddy S, Chan J. Body mass index, waist circumference and waist hip ratio as predictors of cardiovascular riska review of the literature. European Journal of Clinical Nutrition. 2010; 64, 16-22. https://doi.org/10.1038/ejcn.2009.68

34. Pathak LA, Shirodkar S, Ruparelia R, Rajebahadur J. Coronary artery disease in women. Indian Heart J. 2017; 69(4): 532-8 https://doi.org/10.1016/j.ihj.2017.05.023

35. Anil OM, Yadav RS, Shrestha N, Koirala S, Shrestha S, Nikhil OM et al. Prevalence of Cardiovascular Risk Factors in Apparently Healthy Urban Adult Population of Kathmandu. J Nepal Health Res Counc 2018 Oct-Dec; 16(41): 438-5. https://doi.org/10.33314/jnhrc.v16i41.1705

36. Thapa SD, KC SR, Gautam S, Gyawali D. Dyslipidemia in type 2 diabetes mellitus. Journal of Pathology of Nepal. 2017;7: 1149-54. https://doi.org/10.3126/jpn.v7i2.17978
37. Sharma SK, Ghimire A, Radhakrishnan J. Prevalence of Hypertension, Obesity, Diabetes, and Metabolic Syndrome in Nepal. International Journal of Hypertension. Volume 2011, Article ID 821971 9 pages. https://doi.org/10.4061/2011/821971

38. Kajingulu FM, Lepiral FB, Mbutiwi FI. Albuminuria Status and Patterns of Dyslipidemia among Type 2 Diabetes Black Patients Managed at a Tertiary Health-care Hospital: A Post hoc Analysis. Saudi J Kidney Dis Transpl 2018; 29(3):649-57.

https://doi.org/10.4103/1319-2442.235175 